\title{
Food insecurity, childhood illness and maternal emotional distress in Ethiopia
}

\author{
Laura C Anderson ${ }^{1, *}$, Ayalew Tegegn ${ }^{2}$, Fasil Tessema ${ }^{2}$, Sandro Galea ${ }^{3}$ and \\ Craig Hadley ${ }^{4}$ \\ ${ }^{1}$ Department of Anthropology, University of Toronto, 19 Russell Street, Toronto, ON M5S 2S2, Canada: \\ ${ }^{2}$ Department of Epidemiology and Biostatistics, Jimma University, Jimma, Ethiopia: ${ }^{3}$ Department of Epidemiology, \\ Mailman School of Public Health, Columbia University, New York, NY, USA: ${ }^{4}$ Department of Anthropology, Emory \\ University, Atlanta, GA, USA
}

Submitted 20 April 2010: Accepted 10 May 2011: First published online 2 August 2011

\begin{abstract}
Objective: The relationship between food insecurity, maternal emotional distress and childhood morbidity in resource-poor settings is not well clarified. The present study aimed to assess independent associations between household food insecurity and childhood morbidity and potential modifications by maternal emotional distress. Design: A cross-sectional survey. A food security scale was used to assess household food insecurity; maternal reports were used to assess recent childhood illness; and the Hopkins Symptom Checklist was used to assess symptoms of emotional distress among mothers.

Setting: The Oromia Region, Ethiopia (rural area).

Subjects: A total of 936 mother-child pairs.

Results: Of 936 children assessed, $22 \cdot 4 \%$ had experienced diarrhoea, $20 \cdot 7 \%$ had cough and $21.5 \%$ had fever in the 2 weeks preceding the interview. Household food insecurity was reported by $39 \%$ of mothers. Greater food insecurity and greater maternal emotional distress were each independently associated with higher prevalence of cough and fever. Among mothers with low emotional distress, food insecurity was associated with a $2 \cdot 3$ times greater odds of diarrhoea in their children. Conclusions: Household food insecurity may increase the risk of childhood illness in rural Ethiopia, and children having mothers with greater emotional distress may be at highest risk. These findings highlight the importance of strengthening policy initiatives aimed at reducing the high prevalence of food insecurity and emotional distress in Ethiopia.
\end{abstract}

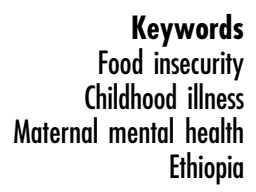

Food insecurity is defined as 'limited or uncertain availability of nutritionally adequate and safe foods or limited or uncertain ability to acquire food in socially acceptable ways $^{\text {,(1) }}$. A significant public health and human rights issue in many low-income countries, food insecurity is highly prevalent in many countries in the Global South and is a significant determinant of multiple childhood health outcomes ${ }^{(2-7)}$.

Three mechanisms have been identified to explain the association between food insecurity and childhood illness. First, food insecurity may be associated with childhood illness because it functions as an indicator of wealth, and wealthier households tend to have healthier children $^{(8)}$. Thus, children from poor families may suffer from malnutrition, which increases the risk of infectious disease, particularly diarrhoeal disease, lower respiratory tract infection, tuberculosis and measles. Second, foodinsecure households may be less likely to engage in high levels of health-care-seeking behaviour, as they may be unwilling or unable to spend resources on childhood health-care because they have to spend their limited resources on food ${ }^{(9)}$.

Third, food insecurity may be associated with childhood illness through its relationship with maternal psychological well-being. Several studies have identified an association between household-level measures of food insecurity and hunger and symptoms of common mental disorders among mothers, which may in turn affect childcare practices. A study of 400 women in rural Tanzania ${ }^{(10)}$ showed that women in food-insecure households scored significantly higher on a measure of symptoms of anxiety and depression. Similar findings have been reported in African and Indian settings ${ }^{(11)}$. We have shown elsewhere that household food insecurity in this rural Ethiopian sample is associated with maternal and paternal symptoms of anxiety and depression ${ }^{(12)}$. The finding that food 
insecurity is associated with symptoms of mental disorders is consistent with a wealth of anthropological data $^{(13)}$, as well as with studies from high-income countries ${ }^{(14)}$. Maternal depression has been found to be associated with poorer child-care behaviours, decreased childhood psychosocial development and functioning and decreased childhood health and nutritional status in both low- and high-income countries ${ }^{(15-21)}$.

These relationships may be of particular importance to public health in sub-Saharan African (SSA) countries where childhood illnesses such as diarrhoea, acute respiratory infection and fever are responsible for considerable short-term and long-term disability and mortality ${ }^{(22)}$. Food insecurity affects over one-third of households in SSA ${ }^{(23)}$, and the number of food-insecure households in SSA is predicted to double by $2020^{(24)}$. In several SSA countries, the impact of food insecurity is likely substantial: in Ethiopia, which was the setting of our current study, over $50 \%$ of the population was undernourished in 2002, with $31 \%$ and $15 \%$ of children under 5 years of age suffering from chronic and acute malnutrition, respectively ${ }^{(25,26)}$.

Although current evidence indicates a high prevalence of both food insecurity and childhood illnesses in Ethiopia, little research has examined this relationship in low-income countries, and to our knowledge no research of this type has been conducted in Ethiopia. Similarly, although one recent analysis shows that maternal depression can be a modifier of the relationship between food insecurity and childhood health in a high-income country ${ }^{(27)}$, to our knowledge no analyses have assessed the indicators of maternal mental disorders or distress as a potential modifier of the relationship between food insecurity and childhood illnesses in Ethiopia. We believe that it is important to recognize that maternal psychological well-being may play an important role in increasing the likelihood of childhood illnesses.

The objective of the present study was to examine the association between experience of household food insecurity, maternal emotional distress (i.e. anxiety and depressive symptoms) and childhood illnesses in families living in a rural area in Ethiopia. We had three hypotheses: (i) food insecurity would predict childhood illnesses even after controlling for potentially confounding individual- and household-level factors; (ii) maternal emotional distress would predict the occurrence of common childhood illnesses; and (iii) the impact of food insecurity on childhood illness would be greatest in households with mothers suffering from high emotional distress.

\section{Materials and methods}

The present study was conducted in rural Ethiopia in the Gilgel Gibe Field Research Center (GGFRC), which is located around the Gilgel Gibe Hydroelectric Dam. The GGFRC is located in the Jimma zone within the Oromia region in south-west Ethiopia. It is approximately $55 \mathrm{~km}$ from Jimma town and $260 \mathrm{~km}$ from Addis Ababa. This is a primarily rural area and the principal occupation is subsistence agriculture. Jimma University conducts an ongoing complete demographic surveillance in the GGFRC, which collects vital data for a complete census of the population comprising more than 8000 households in the area. This census is part of a network of surveillance systems in Ethiopia aimed at a comprehensive assessment of population health. Records are updated several times each year and the community supports these activities.

The Gilgel Gibe Growth and Development Study (GGGDS) was a cohort study of families drawn from the demographic surveillance area focused on adult mental health and childhood development. The study involves questionnaire and anthropometric information collected from the parents of children aged 9-30 months and from developmental assessments conducted on the children. The data analysed in the present study were collected in June and July 2007. A structured questionnaire was developed and administered to participants by nine interviewers. The questionnaire included 159 questions on: children's developmental milestones; caregiving and feeding practices; access to health-care and children's immunization status; maternal anxiety and depression and past traumatic events; and socio-economic status (SES) of the household. Questionnaires and consent documents were developed in English and translated and back-translated into Amharic and Affan Oromifa. Interviewers took a week-long training course that included practice interviewing and role-playing. Following training, interviewers undertook a pilot study in the nearby communities outside the GGFRC and the data were checked for consistency, outliers and for missing values. After the pilot study, interviewers and investigators met to discuss experiences and issues and to finalize the questionnaire. The final questionnaires for men and women were administered separately to husbands and wives at their houses in a private area. Written informed consent was obtained from all participants. The Institutional Review Boards of the University of Michigan, Jimma University and Emory University reviewed and approved the study protocol. The study size comprised 1016 households. All data were de-identified. A total of 1016 maternal or children's questionnaires and 960 paternal questionnaires were completed.

\section{Outcome variables}

We used four dichotomous measures of recent childhood illness as outcome measures. Mothers were asked whether their child had had diarrhoea, cough (an identifiable symptom of respiratory tract infections) or fever (an identifiable symptom predominantly of malaria) in the past 2 weeks before the date of interview. One outcome variable was created for each illness: if the mother reported that the child had experienced the illness in the past 2 weeks, the illness was coded as 1; otherwise it was coded as 0 . A fourth outcome variable indicating whether 
the child had had any one of the illnesses was created by summing the values of 'diarrhoea', 'cough' and 'fever', and coding 1 if the sum was $\geq 1$ and as 0 if the sum was 0 .

\section{Primary predictors}

Household SES was measured by asking husbands to respond to a set of material assets, stating whether or not the household possessed each asset, and coded as 1 if the household possessed the asset and 0 if the household did not possess the asset. The set of items included twenty assets, including various types of livestock, electronic equipment, household characteristics and house ownership. Women provided corresponding responses to some of the material items and these were highly associated with their partner's responses. Therefore, we used the responses of men as indicators of household SES. Items were summed and household SES was categorized on the basis of whether the household's summed item total was in the highest, middle or lowest tertile.

Household-level food insecurity was measured using a seven-item scale based on those used and validated previously in diverse settings in low-income countries ${ }^{(28-30)}$. Mothers and fathers were asked separately whether in the past 3 months: (i) they had worried about running out of food; (ii) they had run out of food; (iii) they had reduced the variety of food for children; (iv) children had not had enough to eat; (v) the respondent or another adult had not eaten enough; (vi) the respondent had spent the whole day without food; and (vii) the household had ever had to ask others for food or money to buy food. These items were scored as yes/no and the analysis showed that the scale had high internal consistency for both mothers (Cronbach's $\alpha=0.93$ ) and fathers (Cronbach's $\alpha=0 \cdot 92$ ). We summed across all items. Respondents giving a positive answer to five or more items on the scale were coded with a value of 1 , indicating food insecurity, with the remaining respondents being coded as 0 , indicating no food insecurity. Food security scores from the mother's and father's questionnaire showed substantial agreement with food insecurity $(>4)$, with $\kappa=0 \cdot 66$, and were highly correlated (Spearman's $\rho=0 \cdot 71, P<0 \cdot 0001$ ). Food security questions from the maternal questionnaire were used for the food insecurity score variable.

We used the Hopkins Symptom Checklist-25 (HSCL) to assess maternal emotional distress. The HSCL is an inventory of anxiety and depressive symptoms and has been used and validated in a range of culturally and economically diverse settings ${ }^{(31,32)}$. The instrument has been used extensively in vulnerable populations, such as in war survivors, and in a range of cross-cultural contexts including Tanzania ${ }^{(13)}$. For each item, respondents are asked to identify whether they have experienced the symptom and the severity of the symptom was assessed on a 4-point Likert scale in the 2 weeks before the survey. These included statements such as 'In the past week how bothered have you been by your heart pounding or racing?'. We summed across all items to create a total score and divided this score into tertiles, creating a variable for maternal emotional distress, coding the lowest tertile as 0 , the middle as 1 and the highest as 2. We were interested in examining the relationship between childhood illness and maternal distress across a range of levels of maternal distress, thus examining women across three levels of distress. The scale showed good internal consistency (Cronbach's $\alpha>0 \cdot 90$ ) and was significantly correlated with stressful life events and with greater reported difficulty in consuming and cooking meals, engaging in farm work, household chores, socializing and maintaining personal hygiene (all $P<0 \cdot 05$ ). The scale, therefore, appears to have adequate internal and external validity but is not a diagnostic tool and has not been validated in the rural Ethiopian setting. We assume, however, that higher scores are indicative of a greater likelihood of emotional distress.

\section{Control variables}

Four control variables were included in the analysis to specify the relationship between food insecurity and childhood illness properly. We included covariates that could be predictive of food insecurity and childhood illness outcomes, which could be driving the associations found between these variables. These were maternal age (years), maternal education (years), children's age (months) and children's gender.

\section{Statistical analyses}

Univariate statistics were used to describe the sample, the prevalence and distribution of key independent variables, and to report the prevalence of diarrhoea, cough, fever and any illness in children. The $\chi^{2}$ test and Student's $t$ test were used to assess the associations between the hypothesized predictor and outcome variables. The $\chi^{2}$ test was used to assess associations between the hypothesized moderator variable and both predictor and outcome variables.

Logistic regression was performed to test the relationship between food insecurity and childhood illness (diarrhoea, cough, fever or any illness) while controlling for household-level (i.e. SES) and individual-level covariates. To examine whether the relationship between food insecurity and childhood illness was modified by maternal distress, interaction terms were created between food insecurity and maternal emotional distress and were assessed for statistical significance $(P<0 \cdot 05)$. Each childhood illness was modelled separately and a model was fit to the 'any illness' outcome. Predicted probability plots of common childhood illnesses by both food insecurity status and maternal emotional distress were constructed to show the magnitude of the bivariate associations. Significant interactions were analysed using subgroup analysis. The criterion for statistical significance was set at $0 \cdot 05$. OR with $95 \%$ CI was used to test the strength of association between predictor and outcome variables. All statistical analyses were carried out using the SAS statistical software package version 9•1 (SAS Institute, Cary, NC, USA). 


\section{Results}

Complete data were available for 936 mother-child pairs. Table 1 shows the individual and household characteristics of this sample. Over one-third (38.9\%) of all mothers reported household food insecurity, defined as a score of $\geq 5$ out of a possible score of 7 . The mean age of mothers responding to the survey was $26 \cdot 5$ (SD 5.6) years. The mean number of school years completed for the mothers was $0 \cdot 7$ (sD $2 \cdot 0$ ) years. The mean age of the children was $21 \cdot 2$ (SD 6.6) months. Just over half of the children were boys.

Approximately one-fifth $(22 \cdot 4 \%)$ of mothers reported that their child had experienced diarrhoeal symptoms in the past 2 weeks. Similarly, 20.7\% reported that their child had experienced cough symptoms in the past 2 weeks and $21.5 \%$ reported that their child had experienced fever symptoms in the past 2 weeks. Comorbidity was common: $14 \cdot 7 \%$ had experienced one of the illnesses in the past 2 weeks, $11 \cdot 0 \%$ had experienced two and $9 \cdot 2 \%$ had experienced all three illnesses.

\section{Bivariate analysis}

Children were significantly more likely to have had cough (26\% v. 18\%, $P<0 \cdot 01$ ), fever (25\% v. 19\%, $P<0 \cdot 05$ ) or more than one illness ( $41 \% v .31 \%, P<0 \cdot 001)$ in the past 2 weeks if their mother reported household food insecurity than if their mother had not reported household food insecurity. Children were also significantly more likely to have had cough (26\% v. $21 \% v .15 \%, P<0 \cdot 01)$, fever $(28 \%$ v. $22 \% v .15 \%, P<0 \cdot 001$ ) or one or more illnesses ( $42 \% v$. $33 \%$ v. 29\%, $P<0 \cdot 001)$ if their mother suffered higher

Table 1 Household and individual characteristics of participants in Gilgel Gibe, 2007

\begin{tabular}{|c|c|}
\hline Household and individual variables & $\%$ \\
\hline \multicolumn{2}{|l|}{ Socio-economic status } \\
\hline Low (0-6 items) & $34 \cdot 3$ \\
\hline Moderate (7-8 items) & $34 \cdot 4$ \\
\hline High $(9-20$ items) & $31 \cdot 4$ \\
\hline \multicolumn{2}{|l|}{ Food security (summed food-secure score $\leq 4$ ) } \\
\hline Secure & $68 \cdot 1$ \\
\hline Insecure & $38 \cdot 9$ \\
\hline \multicolumn{2}{|l|}{ Mother's age (years) } \\
\hline Mean & $26 \cdot 5$ \\
\hline SD & $5 \cdot 6$ \\
\hline Mothers with $<1$ year of education & $84 \cdot 1$ \\
\hline \multicolumn{2}{|l|}{ Maternal emotional distress } \\
\hline Low & $32 \cdot 9$ \\
\hline Moderate & $32 \cdot 0$ \\
\hline High & $35 \cdot 1$ \\
\hline \multicolumn{2}{|l|}{ Gender of child } \\
\hline Male & $52 \cdot 2$ \\
\hline Female & $47 \cdot 8$ \\
\hline \multicolumn{2}{|l|}{ Child's age (months) } \\
\hline Mean & $21 \cdot 2$ \\
\hline SD & $6 \cdot 6$ \\
\hline Children with diarrhoea in the past 2 weeks & $22 \cdot 4$ \\
\hline Children with cough in the past 2 weeks & $20 \cdot 7$ \\
\hline Children with fever in the past 2 weeks & $21 \cdot 5$ \\
\hline $\begin{array}{l}\text { Children with any illness (diarrhoea, cough or fever) } \\
\text { in the past } 2 \text { weeks }\end{array}$ & $35 \cdot 1$ \\
\hline
\end{tabular}

emotional distress (compared with medium and low emotional distress). Mothers in food-insecure households were significantly more likely to suffer from high emotional distress compared with mothers in food-secure households (46\% v. $25 \%$, respectively, $P<0 \cdot 0001$ ). The predicted probability of all three illnesses was higher in food-insecure houses than in those that were food secure (Fig. 1). Similarly, the predicted probability of illness increased with increasing severity of symptoms of maternal emotional distress (Fig. 2). Children with illnesses were significantly younger than those without illnesses in the case of diarrhoea (mean $=19 v .22$ months, respectively, $P<0 \cdot 0001$ ), fever (mean $=20 v .21$ months, $P<0 \cdot 001)$ and one or more illnesses (mean $=20 v .22$ months, $P<0 \cdot 0001$ ). Illness was not associated with children's gender, maternal age, maternal education or SES (Table 2).

\section{Multivariate analysis}

In the multivariate models (Table 3), food insecurity was a significant predictor of diarrhoea $(\mathrm{OR}=1 \cdot 44,95 \% \mathrm{CI}$

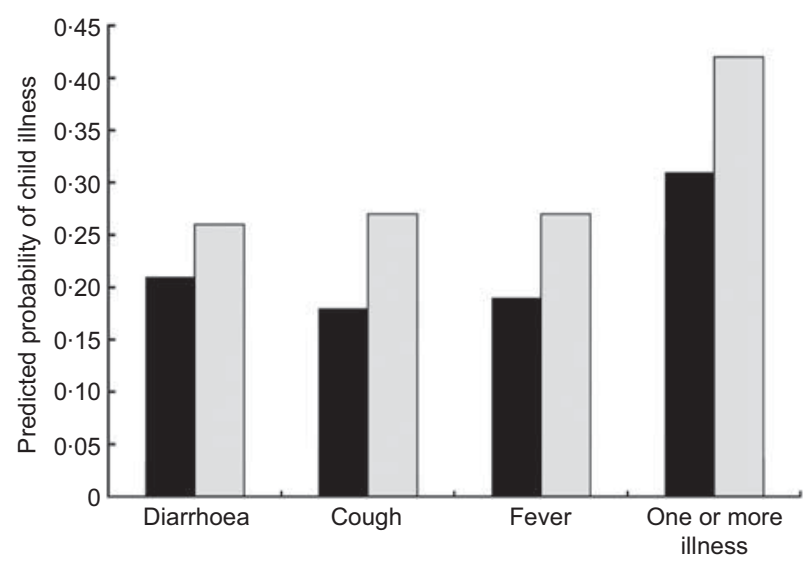

Fig. 1 Predicted probability of child illness by food-security level in Gilgel Gibe, 2007 ( $\square$, food secure; $\square$, food insecure)

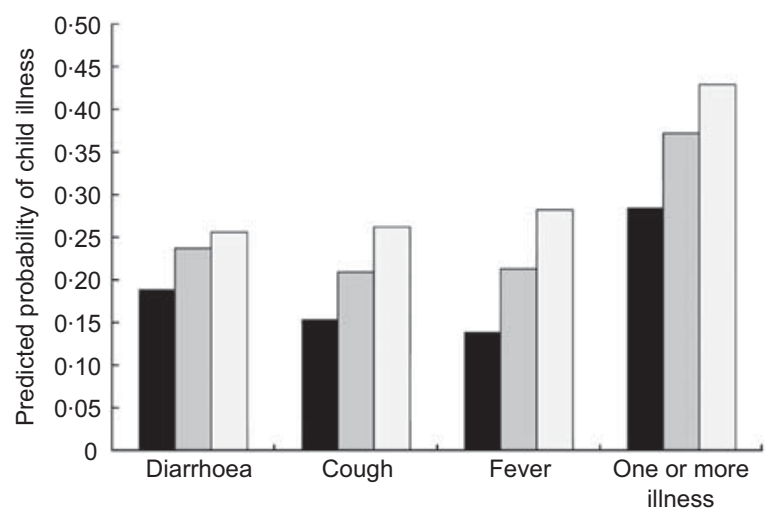

Fig. 2 Predicted probability of child illness by maternal emotional distress (MED) level in Gilgel Gibe, 2007 ( $\square$, low MED; $\square$, moderate MED; $\square$, high MED) 
Table 2 Bivariate associations between predictor variables and childhood illnesses in Gilgel Gibe, 2007†

\begin{tabular}{|c|c|c|c|c|}
\hline & $\begin{array}{l}\text { Diarrhoea in the } \\
\text { past } 2 \text { weeks }\end{array}$ & $\begin{array}{l}\text { Cough in the } \\
\text { past } 2 \text { weeks }\end{array}$ & $\begin{array}{c}\text { Fever in the past } \\
2 \text { weeks }\end{array}$ & $\begin{array}{l}\text { Any illness in the } \\
\text { past } 2 \text { weeks }\end{array}$ \\
\hline & $\%$ & $\%$ & $\%$ & $\%$ \\
\hline \multicolumn{5}{|l|}{ Food security } \\
\hline Secure & $20 \cdot 8$ & $17 \cdot 5$ & $19 \cdot 1$ & $31 \cdot 1$ \\
\hline Insecure & $24 \cdot 8$ & $25 \cdot 7$ & $25 \cdot 4$ & $41 \cdot 3$ \\
\hline$P$ & 0.14 & $<0.01$ & 0.02 & $<0.01$ \\
\hline \multicolumn{5}{|c|}{ Maternal emotional distress } \\
\hline Low & $18 \cdot 7$ & $15 \cdot 2$ & $14 \cdot 6$ & $28 \cdot 9$ \\
\hline Medium & $23 \cdot 4$ & $21 \cdot 0$ & $22 \cdot 2$ & $32 \cdot 7$ \\
\hline High & $24 \cdot 9$ & $25 \cdot 5$ & $27 \cdot 5$ & $42 \cdot 9$ \\
\hline$P$ & 0.13 & $<0.01$ & $<0.01$ & $<0.01$ \\
\hline \multicolumn{5}{|l|}{ Gender of child } \\
\hline Male & $21 \cdot 6$ & $21 \cdot 2$ & $22 \cdot 0$ & $35 \cdot 8$ \\
\hline Female & $23 \cdot 1$ & $20 \cdot 0$ & $20 \cdot 9$ & $34 \cdot 1$ \\
\hline$P$ & 0.54 & 0.63 & 0.68 & 0.57 \\
\hline \multicolumn{5}{|c|}{ Socio-economic status } \\
\hline Low $(0-6)$ & $24 \cdot 9$ & $21 \cdot 9$ & $22 \cdot 1$ & $38 \cdot 3$ \\
\hline Moderate (7-8) & $21 \cdot 1$ & $18 \cdot 7$ & $21 \cdot 7$ & 33.0 \\
\hline High $(9-20)$ & $22 \cdot 8$ & $23 \cdot 6$ & $22 \cdot 6$ & $35 \cdot 4$ \\
\hline$P$ & 0.52 & 0.31 & 0.97 & 0.38 \\
\hline \multicolumn{5}{|c|}{ Mother's age (years) } \\
\hline Mean & $26 \cdot 3$ & $26 \cdot 8$ & $26 \cdot 7$ & $26 \cdot 6$ \\
\hline SD & $5 \cdot 3$ & $5 \cdot 8$ & $5 \cdot 8$ & $5 \cdot 5$ \\
\hline$P \ddagger$ & $0 \cdot 41$ & 0.44 & 0.66 & 0.89 \\
\hline \multicolumn{5}{|c|}{ Mother's education (years) } \\
\hline 0 & $22 \cdot 6$ & $21 \cdot 0$ & $21 \cdot 8$ & $35 \cdot 3$ \\
\hline$\geq 1$ & $21 \cdot 7$ & $18 \cdot 6$ & $20 \cdot 0$ & $33 \cdot 8$ \\
\hline $\bar{P}$ & 0.82 & 0.50 & 0.62 & 0.71 \\
\hline \multicolumn{5}{|c|}{ Child's age (months) } \\
\hline Mean & $18 \cdot 74$ & $20 \cdot 5$ & $19 \cdot 6$ & $19 \cdot 8$ \\
\hline SD & $6 \cdot 4$ & $6 \cdot 8$ & 6.5 & $6 \cdot 5$ \\
\hline$P \ddagger$ & $<0.01$ & $0 \cdot 13$ & $<0.01$ & $<0.01$ \\
\hline
\end{tabular}

+Unless otherwise noted, $P$ values represent $\chi^{2}$ test results.

‡Student's $t$ test.

Table 3 Multivariate logistic equation models predicting childhood illness, Gilgel Gibe, 2007

\begin{tabular}{|c|c|c|c|c|c|c|c|c|}
\hline \multirow[b]{2}{*}{ Variable } & \multicolumn{2}{|c|}{ Diarrhoea } & \multicolumn{2}{|c|}{ Cough } & \multicolumn{2}{|c|}{ Fever } & \multicolumn{2}{|c|}{ Any illness } \\
\hline & OR & $95 \% \mathrm{Cl}$ & OR & $95 \% \mathrm{Cl}$ & OR & $95 \% \mathrm{Cl}$ & OR & $95 \% \mathrm{Cl}$ \\
\hline $\begin{array}{l}\text { Food insecurity } \\
\text { Emotional distresst }\end{array}$ & $1 \cdot 44^{*}$ & $1 \cdot 03,2 \cdot 02$ & $1 \cdot 42^{\star}$ & $1 \cdot 04,2 \cdot 02$ & $1 \cdot 53^{*}$ & $1 \cdot 09,2 \cdot 14$ & $1 \cdot 56^{\star *}$ & $1 \cdot 16,2 \cdot 09$ \\
\hline Middle & $1 \cdot 29$ & $0.85,1.94$ & $1 \cdot 35$ & $0 \cdot 90,2 \cdot 10$ & $1 \cdot 57^{*}$ & $1 \cdot 03,2 \cdot 48$ & 1.09 & $0.80,1.62$ \\
\hline $\begin{array}{l}\text { High } \\
\text { SESt }\end{array}$ & $1 \cdot 50$ & $0 \cdot 98,2 \cdot 24$ & $1 \cdot 81^{\star *}$ & $1 \cdot 18,2 \cdot 72$ & $2 \cdot 41^{\star \star \star \star}$ & $1 \cdot 50,3 \cdot 62$ & $1 \cdot 78^{\star *}$ & $1 \cdot 23,2 \cdot 50$ \\
\hline Middle & 0.85 & $0.58,1.26$ & 0.88 & $0.59,1.30$ & $1 \cdot 14$ & $0.73,1.57$ & 0.88 & $0.63,1.22$ \\
\hline High & $1 \cdot 11$ & $0 \cdot 71,1 \cdot 64$ & $1 \cdot 27$ & $0 \cdot 89,2 \cdot 02$ & $1 \cdot 30$ & $0 \cdot 87,2 \cdot 02$ & $1 \cdot 09$ & $0.80,1.57$ \\
\hline Child sex & 1.02 & $0.74,1.40$ & 0.95 & $0 \cdot 69,1 \cdot 32$ & 0.99 & $0.71,1.35$ & 0.88 & $0 \cdot 67,1 \cdot 17$ \\
\hline Maternal age & $1 \cdot 00$ & $0.97,1.02$ & $1 \cdot 00$ & $0.98,1.01$ & $1 \cdot 00$ & $0.97,1.03$ & $1 \cdot 00$ & $0.98,1.02$ \\
\hline Maternal education & 1.09 & $0.71,1.65$ & $1 \cdot 14$ & $0 \cdot 72,1 \cdot 78$ & $1 \cdot 23$ & $0.77,1.88$ & $1 \cdot 21$ & $0.78,1.66$ \\
\hline Child age & $0.93^{\star \star \star \star}$ & $0.91,0.95$ & 0.98 & $0.96,1.00$ & $0.95^{\star \star \star \star}$ & $0.93,0.97$ & $0.95^{\star \star \star *}$ & $0.93,0.97$ \\
\hline
\end{tabular}

SES, socio-economic status.

${ }^{\star} P<0.05,{ }^{* *} P<0.01,{ }^{* * *} P<0.001,{ }^{* * * *} P<0.0001$

tCompared with referent group (low).

$1 \cdot 03,2 \cdot 02)$, cough $(\mathrm{OR}=1 \cdot 42,95 \% \mathrm{CI} 1 \cdot 04,2 \cdot 02)$, fever $(\mathrm{OR}=1 \cdot 53,95 \% \mathrm{CI} 1 \cdot 09,2 \cdot 14)$ and one or more illness $(\mathrm{OR}=1 \cdot 56,95 \% \mathrm{CI} 1 \cdot 16,2 \cdot 09)$ after controlling for individual and household variables and potential confounders. Moderate levels of maternal emotional distress was a significant predictor of fever (OR $=1 \cdot 57,95 \%$ CI $1 \cdot 03,2 \cdot 48)$, and high levels of emotional distress were predictive of cough $(\mathrm{OR}=1 \cdot 81,95 \% \mathrm{CI} 1 \cdot 18,2 \cdot 72)$, fever $(\mathrm{OR}=2 \cdot 41$,
95\% CI $1.50,3.62)$ and any illness (OR $=1.78,95 \%$ CI $1 \cdot 23,2 \cdot 50)$, after controlling for confounders. Younger age of children remained a significant predictor of diarrhoea $(\mathrm{OR}=0.93,95 \%$ CI $0.91,0.95)$, fever $(\mathrm{OR}=0.95,95 \%$ CI $0 \cdot 93,0 \cdot 97)$ or one or more illness (OR $=0.95,95 \%$ CI $0 \cdot 93,0 \cdot 97)$, but not of cough (OR $=0 \cdot 98,95 \%$ CI $0 \cdot 96$, 1.00). SES, children's sex and maternal age and education were not significant predictors of childhood illness. 
We fit several models with interactions and performed subgroup analysis to explore our third hypothesis. The association between diarrhoea and food insecurity was modified by maternal emotional distress. Among families in which the mother was not suffering from emotional distress, children from food-insecure households were more than twice as likely to have diarrhoea $(\mathrm{OR}=2 \cdot 33$, $95 \%$ CI $1 \cdot 58,3 \cdot 11$ ). However, among families in which the mother was suffering from emotional distress, food insecurity was not a risk factor for diarrhoea $(\mathrm{OR}=0 \cdot 87$, $95 \%$ CI $0 \cdot 22,3 \cdot 49)$. In our subgroup analysis, among families that were food secure, children having mothers with high emotional distress were $2 \cdot 3$ times as likely to have diarrhoea $(\mathrm{OR}=2 \cdot 30,95 \% \mathrm{CI} 1 \cdot 69,2 \cdot 94)$. Among food-insecure families, maternal emotional distress was not a risk factor for diarrhoea $(\mathrm{OR}=0 \cdot 84,95 \%$ CI $0 \cdot 44,1 \cdot 61)$.

\section{Discussion}

In the present representative sample of households in a rural area of Ethiopia, we found that household food insecurity and maternal emotional distress were independent predictors of children having had illness in the 2 weeks before the survey. We found that maternal emotional distress modified the relationship between household food insecurity and diarrhoea.

Food insecurity status was associated with increased risk of diarrhoea, cough or fever, independent of children's gender and age, mothers' age and educational level, and SES. These results are consistent with similar studies from high-income countries ${ }^{(7)}$. To our knowledge, our study is among the few to use an experience-based food security measure to assess the association between food insecurity and childhood health outcomes, and these results are particularly pertinent in Ethiopia's chronically food-insecure environment ${ }^{(33)}$. Because this association between food insecurity and all childhood illnesses was found after controlling for SES, it appears that factors beyond SES and food availability influence the risk of childhood illness. A possible hypothesis is that stress due to food insecurity and the accompanying maternal distress may affect childcare behaviours, which in turn may lead to childhood illness. Furthermore, the risk of childhood malnutrition, another risk factor for childhood illnesses, may increase with increasing food insecurity.

Maternal emotional distress was also associated with increased diarrhoea, cough or fever risk, independent of children's gender and age, mothers' age and educational level, and SES. These results are consistent with results from a cohort study conducted in Pakistan, which found that the relative risk of diarrhoea in infants with depressed mothers was 2.5 times greater than that for infants with mothers not suffering from depression ${ }^{(20)}$. The consistency of our results with those in other contexts suggests that the scale is an accurate indicator of emotional distress. We also found that the association between food insecurity and diarrhoea was modified by maternal emotional distress. Our results show that, among mothers without emotional distress, children in food-insecure households were more than twice as likely to have had diarrhoea or one or more illnesses; however, among mothers with emotional distress, food insecurity did not predict any childhood illness. This result was contrary to our hypothesis that the impact of food insecurity on childhood illness would increase as maternal distress increased. One explanation for this unexpected result is that mothers with high emotional distress have poor care practices regardless of their food security status; as a result, food security status may not affect their child's health. Nevertheless, these results highlight the impact of both food insecurity and maternal mental health on childhood health outcomes in the chronically food-insecure context of rural Ethiopia.

One explanation for the association between maternal emotional distress and childhood illness is that depressed mothers display poor health-seeking behaviours ${ }^{(15)}$. Distressed mothers can be more withdrawn in their interactions with their children, and provide care for their children in different ways ${ }^{(34,15)}$. Poor mental health may have an impact on the demanding task of child-care and may lead to a decrease in the quality of care, as well as in feeding and health-seeking behaviours ${ }^{(35)}$. This difference in feeding behaviours between distressed and nondistressed mothers could have important implications for childhood health, as a less active role in their children's feeding and care is linked to decreased nutrient intake and childhood development ${ }^{(36-38)}$. Good child-care practices have been shown to be an effective means by which to mitigate the effects of poverty on children's nutrition ${ }^{(39)}$. Depressed mothers may also have poorer care practices, particularly during critical times of childhood illness. These feeding and care practices may have an effect on childhood illnesses in our study sample.

The household food insecurity measure that we used appears to be a valid tool in rural Ethiopia for several reasons. The least severe items were endorsed at a higher frequency compared with the most severe items. Household food insecurity also predicted the independently reported food security status of youth living within those households, as well as lower dietary diversity and lower animal-source food consumption. Further, households with higher incomes were less likely to be categorized as food insecure $(P<0 \cdot 001)^{(40,41)}$. This association found between food insecurity and income and dietary diversity is similar to the analytical strategy used in a validation study of the US Department of Agriculture's (USDA) food security scale in Brazil $^{(42)}$. The high consistency that we found between both mothers and fathers also suggests that the scale is understandable and the results repeatable in this linguistic and cultural context. Other studies have also reported on the psychometric properties of a modified USDA food security scale, finding that food insecurity is strongly 
associated with measures of mental health morbidity ${ }^{(10,42)}$. The consistency of these results to our study's results lends further strength to our measure of food insecurity.

The present study has several limitations. First, the study is based on a cross-sectional analysis, and as such we are limited in our ability to determine the direction of association between exposures to food insecurity and subsequent childhood illness. Thus, families with chronically ill children may be more at risk for food insecurity because of increased resources being used to treat sick children. However, a US cohort study has found an inverse association between household food insecurity and children's cognitive development and weight gain ${ }^{(18)}$, suggesting that there is a mechanism linking food insecurity with poor childhood health and development. Our results may indicate that a similar mechanism exists in the setting of a low-income country.

The HSCL has not, to our knowledge, been validated in rural Ethiopian populations, and thus no conclusions can be drawn on the clinical psychiatric diagnoses in the study population. However, the HSCL has been used in many different contexts and has been found to be a valid tool in populations subjected to emergency situations ${ }^{(43,44)}$. We assume that higher scores indicate higher levels of distress, as indicated in all other settings where it has been applied. In addition, because scores were significantly associated with perceived functioning, it appears to have adequate external validity ${ }^{(45)}$. A final limitation of the present study is that both predictor (food insecurity) and outcome (childhood illness) variables were determined using recall from the mother, thus creating the possibility for same-source bias. We chose to use the mothers' recall of food insecurity because women are generally responsible for food preparation in a household and are thus the best source for an accurate assessment of household food insecurity ${ }^{(46)}$. Mothers' and fathers' measures of food insecurity in our survey showed a high level of agreement $(\kappa=0 \cdot 66)$.

\section{Future research}

An ethnographic study examining the type of care behaviours affected by food insecurity and maternal mental health would help elucidate the findings of the present study further. In addition, future studies should collect information on caregiver's health-seeking behaviour in both food-secure and food-insecure households to assess the impact of limited resources on health-seeking behaviour. Finally, data collection efforts should include indicators of childhood health that do not rely on maternal recall.

\section{Policy implications}

Our findings suggest that even by the age of 2 years a family's food security status may have an impact on a child's propensity to contract diarrhoeal, respiratory and fever-causing infections in a rural Ethiopian community, and that children with mothers experiencing high emotional distress are more likely to contract these illnesses. The findings highlight the importance of strengthening policy initiatives aimed at reducing the high prevalence of food insecurity in Ethiopia and the role of maternal symptoms of mental disorders, which must be treated in order to maximize childhood health. Such efforts will contribute to increasing the quality of child-care practices, as well as contribute to young children's development in this chronically food-insecure environment.

\section{Acknowledgements}

Funding for the present project was provided by the Michigan Interdisciplinary Center on Social Inequality, Mind and Body. The authors have no conflict of interest to declare. C.H., F.T., A.T. and S.G. contributed to the study design; C.H., F.T., A.T. and S.G. contributed to the study implementation; L.C.A. and C.H. contributed to the data analysis; L.C.A. contributed to the write-up; C.H. S.G., F.T. and A.T contributed to the critical review of the manuscript. The authors are grateful to the local staff of GGGDS and colleagues at Jimma University for their support and work during data collection and analysis and to the community of Gilgel Gibe for their ongoing support and participation in this study.

\section{References}

1. Bickel G, Nord M, Price C et al. (2000) Guide to Measuring Household Food Security. Alexandria, VA: USDA, FNS.

2. Kendall A, Olson C \& Frongillo E (1996) Relationship of hunger and food insecurity to food availability and consumption. J Am Diet Assoc 96, 1019-1024.

3. Olson C (1999) Nutrition and health outcomes associated with food insecurity and hunger in the US. J Nutr 129, Suppl. 2S, S521-S524.

4. Casey P, Szeto K, Lensing S et al. (2001) Children in foodinsufficient, low-income families: prevalence, health, and nutrition status. Arch Pediatr Adolesc Med 155, 508-514.

5. Cook J, Frank D, Berkowitz C et al. (2004) Food insecurity is associated with adverse health outcomes among human infants and toddlers. J Nutr 134, 1432-1438.

6. Cook J, Frank D, Levenson S et al. (2006) Child food insecurity increases risks posed by household food insecurity to young children's health. J Nutr 136, 1073-1076.

7. Casey P, Szeto K, Robbins J et al. (2005) Child healthrelated quality of life and household food security. Arch Pediatr Adolesc Med 159, 51-56.

8. Committee on Pediatric Research (2000) Race/ethnicity, gender, socioeconomic status - research exploring their effects on child health: a subject review. Pediatrics 105, 1349-1351.

9. Kushel M, Gupta R, Gee L et al. (2006) Housing instability and food insecurity as barriers to health care among lowincome Americans. J Gen Intern Med 21, 71-77.

10. Hadley C \& Patil C (2006) Food insecurity in rural Tanzania is associated with maternal anxiety and depression. $\mathrm{Am} \mathrm{J}$ Hum Biol 18, 359-368.

11. Patel V, Araya R, de Lima M et al. (1999) Women, poverty and common mental disorders in four restructuring societies. Soc Sci Med 49, 1461-1471. 
12. Hadley C, Galea S, Tegegn A et al. (2008) Food insecurity, stressful life events, and the risk of common mental disorders in East Africa: evidence from the Gilgel Gibe Growth and Development Study. J Epidemiol Community Health 62, 980-986.

13. Pike I \& Patil C (2006) Understanding women's burdens: preliminary findings on psychosocial health among Datoga and Iraqw women of northern Tanzania. Cult Med Psychiatry 30, 299-330.

14. Whitaker R, Phillips S \& Orzol S (2006) Food insecurity and the risks of depression and anxiety in mothers and behavior problems in their preschool-aged children. Pediatrics 118, e859-e868.

15. Minkovitz C, Strobino D, Scharfstein D et al. (2005) Maternal depressive symptoms and children's receipt of health care in the first 3 years of life. Pediatrics 115, 306-314.

16. Leiferman J (2002) The effect of maternal depressive symptomatology on maternal behaviors associated with child health. Health Educ Behav 29, 596-607.

17. Weinberg M \& Tronick E (1998) The impact of maternal psychiatric illness on infant development. J Clin Psychiatry 59, 53-61.

18. Jyoti D, Frongillo E \& Jones S (2005) Food insecurity affects school children's academic performance, weight gain, and social skills. J Nutr 135, 2831-2839.

19. Taj R \& Sikander K (2003) Effects of maternal depression on breast-feeding. J Pak Med Assoc 53, 1-4.

20. Rahman A, Iqbal Z, Bunn J et al. (2004) Impact of maternal depression on infant nutritional status and illness. Arch Gen Psychiatry 61, 946-952.

21. Black M, Banqui A, Zaman K et al. (2009) Maternal depressive symptoms and infant growth in rural Bangladesh. Am J Clin Nutr 89, 951S-957S.

22. UNICEF (2004) State of the World's Children. Geneva: UNICEF.

23. Benson T (2004) Africa's Food and Nutrition Situation: Where Are We and How Did We Get Here? Washington, DC: IFPRI.

24. Food and Agricultural Organization of the United Nations (2006) The State of Food Insecurity in the World, 2006. Rome: FAO.

25. Macro International (2006) Ethiopia Demographic and Health Survey 2005. Addis Ababa, Ethiopia and Calverton, MD: Central Statistical Authority and ORC Macro.

26. Food and Agricultural Organization of the United Nations (2004) The State of Food Insecurity in the World, 2004. Rome: FAO.

27. Bronte-Tinkew J, Zaslow M, Capps R et al. (2007) Food insecurity works through depression, parenting, and feeding to influence overweight and health in toddlers. J Nutr 137, 2160-2165.

28. Swindale A \& Bilinsky P (2006) Development of a universally applicable household food insecurity measurement tool: process, current status, and outstanding issues. J Nutr 136, Suppl. 5S, 1449S-1452S.

29. Melgar-Quinonez H, Zubieta A, McNelly B et al. (2006) Household food insecurity and food expenditure in
Bolivia, Burkina Faso, and the Philippines. J Nutr 136, Suppl. 5S, 1431S-1437S.

30. Frongillo E \& Nanama S (2006) Development and validation of an experience-based measure of household food insecurity within and across seasons in northern Burkina Faso. J Nutr 136, Suppl. 5S, 1409S-1419S.

31. Derogatis L, Lipman R, Rickels K et al. (1974) The Hopkins Symptom Checklist (HSCL): a measure of primary symptom dimensions. Mod Probl Pharmacopsychiatry 7, 79-110.

32. Kaaya S, Fawzi M, Mbwambo J et al. (2002) Validity of the Hopkins Symptoms Checklist-25 amongst HIV-positive pregnant women in Tanzania. Acta Psychiatr Scand 106, 9-19.

33. Kaluski D, Ophir E \& Amede T (2002) Food security and nutrition: the Ethiopian case for action. Public Health Nutr 5, 373-381.

34. Field T (1998) Maternal depression effects on infants and early interventions. Prev Med 27, 200-203.

35. Patel V, Rahman A, Jacob K et al. (2004) Effect of maternal mental health on infant growth in low income countries: new evidence from South Asia. BMJ 6, 70-80.

36. Engle P, Bentley M \& Pelto G (2000) The role of care in nutrition programmes: current research and a research agenda. Proc Nutr Soc 59, 25-35.

37. Pollitt E, Gorman K, Engle $\mathrm{P}$ et al. (1993) Early Supplementary Feeding and Cognition: Effects Over Two Decades. Chicago, IL: Society for Research in Child Development/University of Chicago Press.

38. Pollitt E, Gorman K, Engle P et al. (1995) Nutrition in early life and the fulfillment of intellectual potential. J Nutr 125, Suppl. 4S, 1111S-1118S.

39. Ruel M, Levin C, Armar-Klemesu M et al. (1999) Good care practices can mitigate the negative effects of poverty and low maternal school on children's nutritional status: evidence from Accra. World Dev 27, 1993-2009.

40. Hadley C, Lindstrom D, Tessema F et al. (2008) Gender bias in the food insecurity experience of Ethiopian adolescents. Soc Sci Med 66, 427-438.

41. Belachew T, Hadley C, Lindstrom D et al. (2011) Gender differences in food insecurity and morbidity among adolescents in Southwest Ethiopia. Pediatrics 134, 1923-1928.

42. Perez-Escamilla R, Segall-Correa A, Maranha L et al. (2004) An adapted version of the U.S. Department of Agriculture Food Insecurity Module is a valid tool for assessing household food insecurity in Campinas, Brazil. J Nutr 134, 1923-1928.

43. Lavik N, Laake P, Hauff E et al. (1999) The use of self-reports in psychiatric studies of traumatized refugees: validation and analysis of HSCL-25. Nord J Psychiatry 53, 17-20.

44. Bolton P, Bass J, Betancourt T et al. (2007) Interventions for depression symptoms among adolescent survivors of war and displacement in northern Uganda. JAMA 298, 519-527.

45. Bolton P \& Tang A (2002) An alternative approach to crosscultural function assessment. Soc Psychiatry Psychiatr Epidemiol 37, 537-543.

46. Quisumbing A, Brown L, Feldstein H et al. (1995) Women: The Key to Food Security. Washington, DC: IFPRI. 